
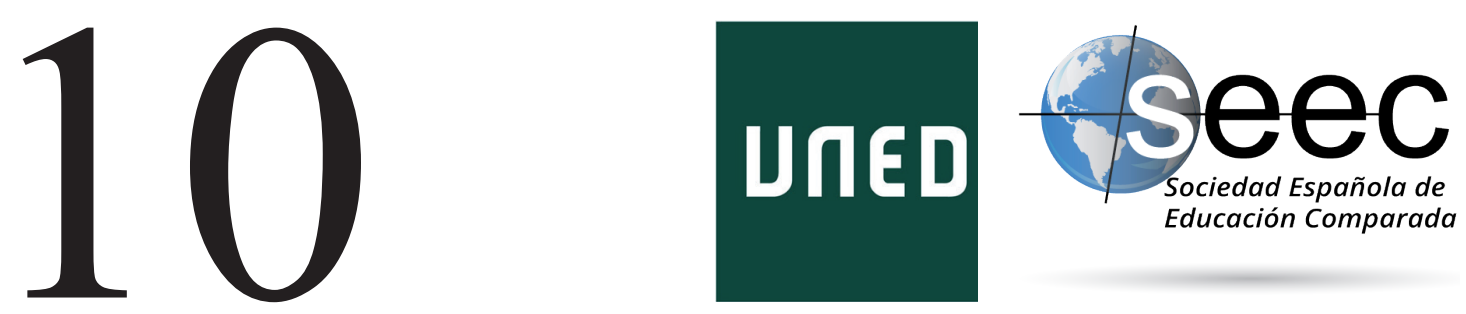

\title{
La educación en los campamentos saharauis: un sistema educativo en el refugio $y$ en el desierto
}

Education in the Saharawi camps: an educational system in the shelter and in the desert

\section{José Antonio Vinagrero Ávila*}

DOI: $10.5944 /$ reec.35.2020.25174

\author{
Recibido: 30 de junio de 2019 \\ Aceptado: 2 de octubre de 2019
}

\footnotetext{
*José Antonio Vinagrero Ávila: Maestro de profesión, se licenció en Pedagogía por la UNED. En este periodo investigó sobre la educación saharaui desplazándose in situ durante tres meses y observando todos los centros educativos. Los resultados supusieron el inicio de sus estudios de Doctorado y publicó junto a Agustín Velloso dos libros en los que se recogen los datos de esta investigación. Experto en este tema coordino el proyecto «Libros de texto en español para el Sáhara» financiado por la AECID. Actualmente dirige un colegio público en Valladolid y sigue estudiando la educación de los saharauis en el refugio. Datos de contacto: E-mail: javinagrero@educa.jcyl.es
} 


\title{
Resumen
}

Cuando en 1975 España abandona a su suerte a los habitantes de la antigua provincia española del Sáhara Occidental, la mayor parte de la población saharaui tiene que huir de sus hogares perseguidos por los ejércitos de Marruecos y Mauritania en la operación conocida como «Ecouvillon» mientras la población civil marchaba a territorio sharaui en «La marcha Verde». En esta huida hacia el desierto encuentran refugio en un territorio inhóspito de la Hamada argelina donde, ubicados en cuatro campamentos, declaran la República Árabe Saharaui Democrática (RASD), organizando los servicios básicos que permitan la supervivencia de la población así como la posibilidad de retorno y gobierno del territorio del Sáhara Occidental en un futuro. Dentro de la dureza de la situación surge algo excepcional y es el eje principal de este artículo. El pueblo saharaui es capaz de crear en los campamentos de refugiados en el desierto, un sistema educativo que permite reducir el analfabetismo en toda la población en general y en la infancia en particular. Han sido capaces de organizar un sistema educativo en el que prácticamente el 100\% de los niños y niñas se encuentran escolarizados, reduciendo el analfabetismo del $90 \%$ de la población en la época colonial, hasta datos semejantes a los de los países desarrollados. En la educación de los campamentos se pueden cursar estudios de educación infantil, primaria, secundaria y también de formación profesional. En este artículo profundizaremos sobre las principales características y dificultades de un sistema educativo estructurado prácticamente sin recursos económicos pero que supone una gran apuesta por la educación como forma de lucha, progreso social y político. También analizaremos el papel del Gobierno español como donante de ayuda humanitaria a este pueblo, así como su responsabilidad política en un conflicto que sigue abierto desde hace más de 40 años, siendo el Sáhara Occidental el único territorio del mundo pendiente de descolonización.

Palabras clave: educación; refugiados; analfabetismo; política educativa; organización escolar; formación del profesorado

\begin{abstract}
When in 1975 Spain leaves to its fate the inhabitants of the former Spanish province of Western Sahara, most of the Saharawi population has to flee their homes chased by the armies of Morocco and Mauritania in the operation known as "Ecouvillon" while the civilian population marched to Saharaui territory in "The Green March". In this flight to the desert find refuge in an inhospitable territory of the Algerian Hamada where, located in four camps, declare the Sahrawi Arab Democratic Republic (SADR), organizing basic services that allow the survival of the population as well as the possibility of return and government of the territory of Western Sahara in the future. Within the hardness of the situation emerges something exceptional and it is the main axis of this article. The Saharawi people are able to create in the desert refugee camps an educational system that reduces illiteracy in the population as a whole and in childhood in particular. They have been able to organize an educational system in which practically $100 \%$ of children are in school, reducing the illiteracy of $90 \%$ of the population, in colonial times, to data similar to those of developed countries. In the education of the camps you can study children's education, primary, secondary and also vocational training. In this article we will go deeper into the main characteristics and difficulties of a structured educational system practically without economic resources, but what represents a great commitment to education as a form of struggle, social and political progress. We will also analyze the role of the Spanish Government as a donor of humanitarian aid to these people, as well as its political responsibility in a conflict that has been open for more than 40 years, with Western Sahara being the only territory in the world pending decolonization.
\end{abstract}

Keywords: education; refugees; illiteracy; educational policy; School organization; teacher education 


\section{Introducción}

El territorio del Sáhara Occidental está ubicado en el continente africano y hace frontera al norte con Marruecos, al sur con Mauritania, al este con Argelia y al oeste con el Océano Atlántico.

El Sáhara Occidental tiene una zona costera y una zona de interior. Dispone de importantes recursos naturales y económicos como las minas de fosfato (principalmente los de la explotación de Fos Bucráa), petróleo y un impresionante banco de pesca en sus caladeros.

La historia del Sáhara Occidental y la historia de España están unidas desde hace muchos años, no en vano es fácil encontrar referencias a este territorio como el Sáhara español. Los detalles históricos de como el Sáhara Occidental pasó a ser una colonia española para después ser una provincia española, en un intento de evitar la descolonización, hasta su total abandono, pueden ser consultados y estudiados en diferentes fuentes bibliográficas, como por ejemplo: Barreñada y Ojeda (2016); Bárbulo (2002); Velloso y Vinagrero (2011) y (2016).

Un rápido resumen histórico para contextualizar lo que a continuación se expone, nos sitúa en noviembre de 1975, al final del régimen de Franco, con el dictador a punto de fallecer y con una situación política interna en España muy delicada. Por otro lado y de forma paralela, cronológicamente hablando, la ONU presiona a España para que se haga efectiva la descolonización del territorio del Sáhara Español, facilitando la independencia de esta provincia siguiendo así los pasos de otros muchos territorios que ya habían sido descolonizados previamente. Esta coyuntura política es aprovechada por el reino de Marruecos, con Hassan II como rey, para reclamar los territorios del Sáhara Español en un intento por apropiarse del territorio a pesar de que el Tribunal Internacional de Justicia de la Haya no encontrase ninguna relación de soberanía entre ambos territorios.

Finalmente el 14 de noviembre de 1975 España entrega la mitad norte del territorio a Marruecos y la mitad Sur a Mauritania firmando lo que se conoce como los Acuerdos Tripartitos de Madrid. Ese es el punto de inicio de la conocida Marcha Verde, una supuesta marcha pacífica donde la población marroquí y mauritana marchaban a liberar el Sáhara Occidental. Pero lo cierto es que además de ese «teatro» pacífico los ejércitos de ambos países, con el apoyo de potencias como EEUU y Francia, intentaron masacrar a la resistencia y la población saharaui iniciando una guerra para apoderarse del territorio. Dicha guerra sigue declarada pero con un alto el fuego acordado desde el año 1991.

Ante estos acontecimientos la población saharaui que tiene capacidad de huir marcha hacia el interior por el desierto intentando alcanzar la frontera argelina. Otra parte de la población, incapaz de realizar la huida, se queda en el territorio bajo el sometimiento y la presión de las fuerzas invasoras.

En pleno camino de huida hacia el refugio, sin el apoyo de España ni de ningún organismo internacional, el pueblo saharaui declara en la localidad de Bir Lehlú, muy cerca de la frontera argelina, la Repúbllica Árabe Saharaui Democrática (RASD).

Esta República asienta a su población en La Hamada argelina, una de las zonas desérticas más inhóspitas de todo el planeta, ubicándose en un principio en cuatro campamentos separados unos de otros, como medida de seguridad ante posibles ataques. 


\section{Creación de un sistema educativo en el refugio}

Desde ese primer momento la RASD empieza a organizarse en muchos ámbitos (sanidad, suministros, desarrollo económico, justicia y asuntos sociales) para establecer la supervivencia de su población y realizan una apuesta contundente con respecto a la educación para revertir los altísimos índices de analfabetismo dejados por la metrópoli española. Apostando por la educación pretenden formar a los futuros dirigentes de la república en su retorno al territorio que les pertenece.

Lo que no sabían los cerca de 40.000 ${ }^{1}$ que llegaron a Argelia en el año 1976 es que más de cuarenta años después, ellos y sus descendientes continuarían refugiados en los mismos campamentos y sin esperanza de una solución al conflicto armado y humano que esto supone.

El índice de analfabetismo de la población saharaui, cuando se asientan en los campamentos de Tindouf ${ }^{2}$, se estima en un $90 \%$ de la población, alcanzando el $96 \%$ si nos referimos exclusivamente a la población femenina. Ante este saldo desalentador donde solo un $10 \%$ de la población sabía leer y escribir una de las principales medidas fue la de enviar al mayor número de niños y jóvenes posible a estudiar a países que reconocieron a la RASD y les ofrecieron su ayuda en esta materia. Generaciones enteras estuvieron más de diez años estudiando en algún país de acogida para poder dirigir en un futuro a la RASD en su camino a la autodeterminación en territorio saharaui.

Esta medida supuso un gran esfuerzo individual y colectivo, donde las familias se vieron separadas de sus hijos y estos sufrieron una aculturación profunda de sus raíces siendo muy difícil su integración en la vida de los campamentos al finalizar sus estudios ${ }^{3}$.

A parte de esta medida, rápidamente en los campamentos se empezaron a crear escuelas donde la población no analfabeta enseñaba a leer y escribir a los niños y a otras personas analfabetas. En un primer momento no eran más que «jaimas» ${ }^{4}$ y la escritura se realizaba sobre la arena del suelo o en pequeños pizarrines. Pero con el tiempo, el aumento de la población y la llegada de ayuda humanitaria, bien de forma directa o a través de proyectos, se fueron creando escuelas de educación infantil (tarbías) y de educación primaria (madrasas) en todos las Dairas de cada uno de los campamentos (Wilayas) ${ }^{5}$.

Además de estas escuelas se han creado escuelas de alfabetización de mujeres, centros de formación profesional, centros de educación secundaria y centros de formación del profesorado. Creando una red de centros sin igual en otras poblaciones en la misma situación de refugio. Esta estructura ha conseguido que el índice de analfabetismo de la población infantil saharaui sea actualmente inferior al $1 \%$, dato equiparable solo a países desarrollados e inimaginable en un país que depende totalmente de la ayuda humanitaria en el refugio.

\footnotetext{
$1 \quad$ Datos obtenidos de la web de ACNUR

2 En ocasiones se denomina así a los campamentos de refugiados saharauis por la cercanía a la población argelina de Tindouf.

3 Para ilustrar esta cuestión en los campamentos encontramos a personas que en aquella época se fueron a estudiar a Cuba y hablan fluidamente el español con acento cubano. A estas personas se las denomina familiarmente como «cubanauis».

4 Se denomina así a las tiendas de campaña instaladas para la vida en los campamentos. Con el tiempo se han ido construyendo pequeños habitáculos de adobe anexos a las mismas.

5 Los campamentos en Hassanía, dialecto árabe saharaui se denominan wilayas suele ser análogo a región, cada wilaya está formado por Darías (ciudades) que a su vez se dividen en forma de cuadrícula en cuatro barrios.
} 


\subsection{La educación infantil}

Las escuelas infantiles se denominan Tarbías, las primeras se crearon en los campamentos en el año 1984, ubicadas estratégicamente en el centro de las Dairas, son edificios de adobe muy simples con un patio central. Estos centros tienen una misión educativa y de acogimiento de los niños. En una Tarbía se cursan tres cursos, desde los 3 a los 5 años, serían los equivalentes al segundo ciclo de educación infantil en España. De los tres cursos, los dos primeros serían de carácter voluntario ${ }^{6}$ y el tercero de carácter obligatorio y preparatorio para la siguiente etapa educativa.

Las tarbías suelen tener unas seis clases, dos por curso. En los dos primeros cursos no existe un currículum educativo com tal y se realizan actividades lúdicas cumpliendo muchas veces una función asistencial y de guardería. El tercer curso dispone de un currículum propio en el que se recogen actividades de lectoescritura, conocimiento numérico y cálculo.

El horario de las Tarbías es solo de mañana y la totalidad de las maestras son mujeres formadas en su inmensa mayoría en la Escuela Nacional 27 de Febrero o en la Escuela Olof Palme. La ratio maestra alumno es elevada y las carencias estructurales y de materiales muy grandes.

\subsection{La educación primaria}

Una vez terminado el tercer curso en la tarbía se pasa a cursar la educación elemental o primaria que se imparte en las madrasas. Los estudios de las madrasas tienen carácter obligatorio para así conseguir escolarizar a toda la población infantil y evitar el analfabetismo en los campamentos.

La educación primaria consta de seis cursos, igual que en el sistema educativo español. Las madrasas abren sus puertas de sábado a jueves, siendo el viernes el único día no lectivo así como la tarde de los miércoles. El horario de las clases es partido, siendo de 9:00 a 13:00 y de 16:00 a 18:00 evitando las horas centrales de máximo calor, en primavera incluso se adelanta la entrada de la mañana siendo la jornada escolar matutina de 8:00 a 12:00.

Durante el tiempo escolar se dispone de treinta minutos de recreo y el resto del tiempo se cursan las asignaturas de Geografía e Historia, Dibujo, Educación Islámica, Matemáticas, Educación Física, Lengua Árabe, Tecnología, Ciencias Naturales y Lengua Española. Se imparten todas ellas en Hassanía7, a excepción de Lengua Española.

El Ministerio de Educación Saharaui no dispone de un currículum propio de enseñanza elemental aunque sí que envían directrices de organización escolar y de gestión de recursos humanos a los centros. Las asignaturas siguen la secuencia de contenidos de la educación argelina a excepción de Lengua española. El mayor intento por desarrollar un currículum propio se centra en la asignatura de Geografía e Historia donde nada tiene que ver la geografía e historia argelina con la del pueblo saharaui.

A parte de los escasos libros que en las aulas se encuentran, el principal material didáctico es la pizarra, que suele estar apoyada en el suelo porque las paredes de adobe no son capaces de sostener su peso.

$6 \quad$ En España el segundo ciclo de educación infantil tiene carácter voluntario pero de obligada asistencia, es decir que las familias deciden si escolarizar o no a sus hijos pero una vez matriculados tienen la obligación de asistir al centro.

$7 \quad$ Dialecto árabe hablado por el pueblo saharaui. 
Los centros tienen una estructura similar a las tarbías, pero con más aulas y un espacio central más amplio donde se desarrolla el recreo, las clases de educación física, la oración, la izada y la arriada de bandera.

Existen treinta madrasas en total en los campamentos con diferentes tamaños, número de alumnado y de profesorado. Según los estudios de campo la media por clase es de 51,56 alumnos, pero la realidad es otra y si visitamos una madrasa será raro encontrar clases que superen los 25 alumnos.

Las madrasas, al igual que las tarbías, se encuentran en los campamentos en número suficiente y bien ubicadas, permitiendo al alumnado desplazarse a las mismas caminando.

Las madrasas tienen enormes carencias y toda la ayuda de pequeños proyectos o cualquier aportación es siempre bien recibida. Tienen escasez de materiales con poco material didáctico, pupitres y sillas desvencijadas, pizarras que no se sostienen en las paredes, escasez de libros de texto, los cuales tienen que ser compartidos, incluso a veces solo existe un ejemplar para el profesor que copia la lección y los ejercicios en la vieja pizarra.

Pero además, también presentan carencias de infraestructura. La más relevante es que las ventanas no suelen tener cristales y para evitar la entrada de sol o del viento del desierto cargado de arena, disponen de unos cuarterones de madera que tienen que estar siempre cerrados. Eso crea ambientes escolares de gran oscuridad, ya que las madrasas, igual que la mayor parte de instalaciones, no disponen de electricidad. El resultado es que el alumnado saharaui estudia en casi total penumbra lo que genera problemas de vista y las instalaciones escolares de adobe endeble son azotadas por las inclemencias del desierto.

Los edificios de las madrasas fueron creados en los años 80. Son construcciones de adobe con techos de zinc muy endebles ante la erosión del desierto. Los saharauis no tienen estructurado un sistema de mantenimiento de sus escuelas por falta de recursos, siendo en la actualidad, la mayor parte de ellas, edificios ruinosos con mucha arena y carentes de elementos básicos como sanitarios.

La evaluación en las madrasas se realiza a través de exámenes escritos en todas las asignaturas, en tres momentos del curso, coincidiendo con la semana anterior a las vacaciones escolares ${ }^{8}$. En el sexto curso los exámenes son elaborados en el ministerio de educación saharaui y son repartidos en los centros por los inspectores de educación y realizados en los centros a lo largo de una semana. En el resto de los cursos los exámenes de cada asignatura los elabora el jefe de cátedra que suele ser el maestro de mayor experiencia en su asignatura en cada madrasa.

La mayor parte del alumnado supera los exámenes, aunque las asignaturas que les suponen un mayor problema suelen ser las de matemáticas y lengua española. La promoción se puede dar hasta con dos asignaturas suspensas siempre y cuando el promedio de todas las asignaturas sea de aprobado. El sistema de notas, al igual que en otros sistemas educativos va desde la mejor nota 10, hasta la peor o, siendo el aprobado el termino medio 5 .

El promedio no es una cuestión menor, sobre todo al terminar la etapa de primaria ya que en las Madrasas los que obtienen mejores promedios tendrán preferencia a la hora de elegir plaza educativa en la educación secundaria. De esta forma una familia cuyos hijos tengan un buen promedio podrán elegir entre alguna de las escuelas ubicadas en los campamentos o la elección de plaza en alguno de los países que ofertan plazas de secundaria, como por ejemplo Argelia, Libia, Rusia,...

8 Sistema bastante similar al modelo educativo español del que los saharauis toman muchas referencias por las relaciones que mantienen con el pueblo español, sus instituciones, ONGs, etc. 


\subsection{La educación Secundaria}

La mayoría de los saharauis que han terminado sus estudios en los campamentos han tenido que salir a otros países a continuar sus estudios, ya que son muy pocas las plazas existentes para estudiar secundaria en los campamentos. En primer lugar por falta de instalaciones y medios para crear estos edificios en número suficiente, pero fundamentalmente por la falta de un profesorado bien formado para tal tarea.

La secundaria se cursa de $7^{\circ}$ a $10^{\circ}$ curso, el alumnado comienza la secundaria con 12 años y se ven obligados a abandonar a sus familias para seguir estudiando en otros lugares lejos de los suyos. Con niños y niñas de esas edades nos volvemos a encontrar con casos de aculturación y de abandono temprano de los estudios por las duras condiciones de vida en las que se encuentran. Por ello, en los últimos años es una prioridad para el Ministerio de Educación Saharaui crear las suficientes plazas escolares de educación secundaria en los campamentos y conseguir un profesorado suficiente en número y formado para el desempeño de esta tarea docente.

Históricamente el único centro que existía en los campamentos para cursar la educación secundaria era la Escuela Nacional 12 de Octubre. Una escuela ubicada a unos veinte kilómetros por el desierto del campamento más cercano y donde el alumnado estudia en régimen de internado. Se trata de un edificio que en un primer momento fue creado con fines militares y que fue reacondicionado para albergar un edificio escolar, aunque las instalaciones y estructura se asemejan más a un cuartel militar que a una escuela.

También se llegó a crear en los campamentos otra escuela de secundaria denominada 9 de junio pero en un temporal de lluvias torrenciales quedó completamente destrozada. Corría el año 2007-2008 y es cuando las autoridades saharauis se plantean reformar la educación secundaria para lograr que los niños y niñas saharauis no abandonen los campamentos para poder continuar sus estudios en la educación secundaria.

La primera medida que se tomó al respecto fue la de aumentar el número de plazas escolares disponibles en la Escuela Nacional 12 de octubre, pasando de unas cuatrocientas cincuenta a mil quinientas plazas. Otra medida es crear escuelas de formación del profesorado, incentivando la profesión. El principal centro de formación del profesorado se ubica en la antigua escuela 9 de junio. Finalmente el ministerio de educación comienza a hacer esfuerzos para crear una red de centros de secundaria en todas las wilayas semejante a la red de tarbías y madrasas ya existentes.

Fruto de estos esfuerzos y con la ayuda económica de países como Cuba y Venezuela, en septiembre de 2011 se inaugura la escuela de secundaria «Simón Bolívar» en el campamento de Smara. El centro dispone de habitaciones para albergar alumnado en régimen de internado además de que a la escuela acudan estudiantes del propio campamento con capacidad para 700 alumnos.

La gran mayoría de los profesores de este centro son jóvenes con carreras universitarias obtenidas en Cuba y que han sido formados pedagógicamente para el desempeño de la labor docente en los propios campamentos.

\subsection{La Formación Profesional}

En los primeros años de refugio la RASD creó en los campamentos la Formación Profesional destinada a enseñar un oficio a aquellas personas que no accedían a la educación secundaria o que no conseguían terminarla. 
Los primeros centros se crearon en los campamentos en los años ochenta, como por ejemplo, el Centro de Formación El Lualí Mustafa, fundado en 1984 ubicado en las instalaciones de la Escuela 12 de Octubre y donde se daba formación relacionada con: motores de automóviles, chapa y pintura, carpintería, administración, electricidad del automóvil, electricidad industrial y soldaduras. Este centro no continúa funcionando ya que en ese edificio, como se ha comentado anteriormente, se ubica una escuela mixta de educación secundaria.

Otro centro de FP es el centro Gazuani, con capacidad para setenta alumnos en régimen de internado y ubicado a unos 5 kilómetros de la sede organizativa de los campamentos en Rabuni. Este centro funciona con el apoyo de instituciones españolas como el Ayuntamiento y la Diputación de Córdoba que son los encargados del mantenimiento y todo el apoyo financiero. En el centro Gazuani se pueden estudiar módulos de electricidad, electrónica, informática básica y montaje de ordenadores. A través de la Universidad de Córdoba este centro da la oportunidad de obtener un título oficial reconocido por una institución española.

Otros centros de FP son los llamados centros de producción como es el caso del de Smara que cuenta con veintidós talleres ocupacionales y de empleo, dirigidos a jóvenes desempleados. Destacar también la escuela de enfermería Abdelfatah a 55 kilómetros de Smara donde se estudia en régimen de internado y la escuela de formación audiovisual «Abidini Kaid Salen» creada por CEAS-Sáhara ${ }^{9}$ como complemento al festival de cine FISAHARA que se celebra anualmente en los campamentos saharauis.

Como se puede observar la mayor parte de los centros de formación profesional están impulsados y sostenidos por entidades extranjeras que a su vez dependen de subvenciones y partidas para poder continuar colaborando en estos proyectos. Esto genera una falta de planificación a largo plazo, diferencias sustanciales entre unos centros y otros, así como graves problemas organizativos en el momento que alguna de las entidades interrumpe su apoyo por falta de financian de forma inmediata.

\subsection{La educación superior}

Para continuar los estudios superiores en alguna universidad los saharauis que habitan en los campamentos de refugiados de Tindouf tienen que conseguir plaza en alguna universidad de algún país que de forma solidaria les concede alguna plaza.

En un principio los saharauis iban al extranjero convencidos de que esa formación les permitiría desarrollar una profesión acorde con sus estudios a la vuelta al territorio del Sáhara Occidental. Pero son muchas las generaciones de jóvenes con estudios universitarios que a la vuelta a los campamentos se han encontrado la misma situación social, sin esperanzas de una solución política y con precariedad laboral. Estas cuestiones hacen que cada vez más familias sean reticentes a enviar a sus familiares a estudiar al extranjero. Por ello, aunque el índice de analfabetismo en la edad infantil es prácticamente inexistente, en lo que respecta a la enseñanza superior universitaria, cada vez son menos los saharauis que obtienen una titulación de esta índole.

Los principales países que acogen alumnado saharaui en carreras universitarias son: Argelia, Libia, Cuba y Venezuela, en menor medida México e Italia. Las plazas ofertadas son negociadas con la RASD que es la que propone un tipo de perfiles u otros en función de las demandas formativas internas.

9 CEAS-Sáhara es la coordinadora estatal de asociaciones solidarias con el Sáhara impulsora de muchos proyectos en los campamentos y defensora de los derechos humanos tanto en territorio ocupado como en los campamentos. 
De todo el alumnado que sale en busca de una titulación superior solo el 50 \% de los mismos logra terminar sus estudios.

Dentro de los campamentos ha habido intentos de creación de universidades incluso con algún módulo a distancia. Normalmente las iniciativas surgen de asociaciones, ONGs, entidades o las propias universidades que intentan cooperar ofreciendo una formación universitaria reglada y con titulación reconocida. Pero las diferencias políticas, el hecho de que los estados occidentales, como España, no reconozcan a la RASD como un estado en el refugio pendiente de descolonizar, hacen muy difícil que estos intentos de creación de cursos universitarios fructifiquen. Por ello la mayor parte de los intentos, aparte de no tener una titulación oficial, se asemejan más en contenido a módulos de formación profesional que a cursos universitarios superiores.

En esta línea existe desde hace diez años la universidad de Tifariti en territorio liberado $^{10}$, pero es una universidad sin consolidar que ofrece cursos de formación de poca duración y que supone más un esfuerzo de reivindicación política del territorio que una universidad funcional.

\subsection{La educación especial}

Haciendo una retrospectiva de todo lo comentado hasta ahora en el presente artículo, nos damos cuenta de que, pese a todas las dificultades posibles: políticas, humanitarias, económicas, formativas, de instalaciones, recursos didácticos, etc. El pueblo saharaui ha sido capaz de crear un sistema educativo en el desierto que ha conseguido paliar el analfabetismo heredado de su época colonial y, gracias a colaboraciones de otros países, formar profesionalmente y en estudios superiores a una parte de su población. Pero esta cuestión excepcional no se queda solo ahí, sino que han sido capaces de crear centros de educación especial que atienden a personas con algún tipo de discapacidad, ya sea física, intelectual o sensorial. La atención educativa de las personas con discapacidad en los campamentos se inicia considerablemente más tarde que la creación de las escuelas «ordinarias», creándose el primer centro de educación especial en el año 1995 en la wilaya de Smara. La capacidad de seguir articulando un sistema que da la posibilidad educativa a todas las personas es algo de admirar.

Cuando se crearon estos centros tenían un carácter asistencial y sus impulsores, muchos de ellos en activo actualmente, cuentan como tenían que ir a las casas de las familias convenciendo a los progenitores de que la asistencia de sus hijos con discapacidad a este tipo de centros les iba a resultar muy beneficioso. En una época en la que cualquier tipo de discapacidad se intentaba ocultar y en una sociedad que había sufrido los estragos de una guerra, donde la población civil había sido bombardeada con napalm y fósforo blanco, el número de personas con discapacidad era considerable sin tener en cuenta todos los heridos de guerra por, entre otras cosas, minas antipersona, aún instaladas en torno al muro de la vergüenza ${ }^{11}$.

Por suerte la educación especial en los campamentos ha evolucionado y actualmente son las propias familias las que contactan con el centro de educación especial de su wilaya $^{12}$ si detectan alguna cuestión significativa. El sistema de educación ordinaria no

10 Se conoce como territorio liberado a la franja de territorio recuperado por el Frente Polisario en la guerra con Marruecos hasta 1991.

11 Muro defensivo que Marruecos levanta dividiendo los territorios del Sáhara Occidental ocupados por Marruecos y la pequeña franja que los saharauis recuperan antes del alto el fuego.

12 Suele haber un centro para personas con discapacidades visuales o ceguera y otro que aglutina a las personas con discapacidad intelectual o de audición y lenguaje por cada una de las wilayas. Las personas con discapacidad física-motórica solo son atendidas en el centro de educación especial de Smara. 
dispone de mecanismos de detección y orientación educativa por lo que es importante que las familias den el primer paso para que esas personas no queden desasistidas.

El objetivo principal de estos centros es lograr educar a estas personas para que sean capaces de aumentar su autonomía personal y su integración dentro de la sociedad. Para conseguir una mayor integración social, los centros crean pequeños talleres de empleo que permiten obtener unos mínimos ingresos económicos a las personas con discapacidad.

$\mathrm{Al}$ existir solo un centro por wilaya, los maestros empiezan su jornada con algún vehículo pasando a recoger a las personas que asisten al centro, dejándolas de nuevo en sus jamas al terminar la jornada lectiva.

La permanencia de las personas con discapacidad en los centros de educación especial se puede prolongar hasta los veintitrés años, momento en el cual tienen que abandonar el centro. En este punto no existen organizaciones o centros que se encarguen de seguir fomentando la integración socioeducativa de estas personas, lo que supone un problema para el individuo, la familia y el resto de la sociedad.

Los problemas de estos centros son similares a los problemas del resto de centros educativos de los campamentos en sus distintas etapas. Quizá se agrave el hecho de disponer de pocos recursos materiales y de personal con formación suficiente para el desempeño de una tarea tan compleja.

Pese a todo, es admirable que un pueblo desplazado en el refugio, con pocos recursos y dependiente totalmente de la ayuda humanitaria, sea capaz de generar una estructura educativa que contemple también la educación especial.

\subsection{La formación del profesorado y el abandono profesional}

En cuanto a la formación inicial del profesorado podemos encontrar varias etapas a lo largo de la creación de este sistema educativo en el desierto. En un primer momento, nada más instalarse en los territorios argelinos, donde el índice de analfabetismo estaba entorno al $90 \%$, eran aquellos que sabían leer y escribir los que enseñaban en las escuelas improvisadas en el desierto.

Cuando empezaron a retornar los jóvenes que fueron a estudiar carreras universitarias a otros países, se consiguió que la mayor parte del personal que trabajaba en las madrasas dispusiera de la titulación de maestro.

Con el paso del tiempo y la llegada de entidades colaboradoras a trabajar en el terreno, así como la donación económica de las familias que en verano participaban en el programa vacaciones en paz $^{13}$, el dinero empezó a tener importancia en los campamentos. Prácticamente hasta el inicio de los años 90 la población saharaui sobrevivía con la ayuda humanitaria donada por organismos internacionales y que la RASD distribuía entre la población. Pero con la llegada de «incentivos» ${ }^{14}$ de las ONGs y la donación de familias, empezó a haber una brecha en los campamentos donde había familias con más posibilidades que otras. Se creó una economía alternativa a la controlada por el estado donde algunas personas podían comprar en Tindouf productos que vendían luego en los campamentos, adquirir vehículos para ejercer como taxistas,etc.

13 El programa de vacaciones en paz consiste en el acogimiento en los meses mas calurosos del verano de niños saharauis por familias de otros países, principalmente españolas. De esta forma se consigue evitar a los niños de entre 7 y 10 años las duras condiciones del verano en el desierto y por otro lado generar vínculos de unión con familias de otros países para lograr su colaboración y el apoyo de su causa. 
Ante la llegada de dinero a la economía saharaui, los maestros vieron que podían ejercer otras profesiones que les repercutieran mayores ganancias. Esta cuestión afectó principalmente a los maestros de español, ya que muchas de las entidades extranjeras, principalmente españolas, necesitaban colaboradores que dominasen el idioma y estos maestros abandonaban la profesión para hacer de traductores.

Esto generó que, poco a poco, los maestros fueran dejando la tarea docente en busca de otras ocupaciones. Una cifra que ilustra este abandono es que la media de permanencia en el cuerpo docente en los campamentos es de 9,75 años, cifra que aumenta en los maestros de árabe que promedian unos 14 cursos mientras que los de español superan por poco los 7 cursos de media.

Por ello, ahora en las escuelas son pocos los maestros (se estima en un $21 \%)^{15}$ con una titulación de magisterio, algunos poseen otro tipo de titulaciones universitarias pero también hay maestros que no tienen ningún tipo de formación (alrededor del 23\%).

También se da el caso de maestros que buscan un segundo «trabajo» para completar los ingresos lo que hace que también aumentase el absentismo de los docentes.

Para frenar esta situación e intentar revertirla, el Ministerio de Educación Saharaui ha empezado a pagar un pequeño incentivo a los maestros, se ha fomentado el hermanamiento de escuelas saharauis con escuelas de otros países para conseguir aportaciones económicas que mejorasen el material, las instalaciones y el incentivo del profesorado. Además se ha creado un centro de formación del profesorado para dar formación a todos aquellos maestros que no tienen ningún tipo de formación inicial a nivel pedagógico y didáctico.

\section{El Gobierno de España: posicionamiento humanitario y político}

Según datos de las Naciones Unidas, el mundo se encuentra en un momento sin precedentes donde existe un gran número de personas desplazadas de sus hogares. Se calcula que sobre 68,5 millones de personas en todo el mundo han tenido que abandonar sus hogares a causa de las guerras y la persecución. Entre ellas, hay casi 25,4 millones de refugiados, de los cuales más de la mitad son menores de 18 años. Además, hay más de 10 millones de personas apátridas a las que se les ha negado una nacionalidad y el acceso a derechos fundamentales, como la educación, sanidad, empleo y libertad de circulación.

Con estas cifras cuantitativas macro, hablar de la población refugiada saharaui en Tindouf donde unas $\mathbf{1 6 5 . 0 0 0}$ personas habitan un pedazo de tierra desértica de la Hamada argelina, puede parecer un dato menor. Pero si nos centramos en cuestiones relacionadas con la responsabilidad y la historia, el padecimiento y la miseria en la que vive este pueblo debería ser una prioridad del Estado español. No solo en lo relacionado con ayuda humanitaria y acogimiento de la población refugiada sino y fundamentalmente, en la toma de medidas para la solución definitiva de un conflicto que se prolonga en el tiempo y en cuyos orígenes, a nivel político, España es el máximo responsable.

Analizaremos a continuación el papel que tiene el gobierno español en materia de cooperación con los refugiados saharauis, así como su posicionamiento político al respecto.

$\mathrm{Al}$ ser un pueblo refugiado en el exilio, la población saharaui depende casi exclusivamente de la ayuda humanitaria. Esta ayuda humanitaria fluctúa en función de las personas censadas en el refugio, por eso no es extraño que no exista una cifra única 
y oficial. Según ACNUR ${ }^{16}$ al inicio de la ocupación del territorio saharaui unas 40.000 personas huyeron a través del desierto hasta la Hamada argelina instalándose en cuatro campos de refugiados. Según esta misma fuente en mayo de 2016 son 165.000 refugiados los que habitan en los campamentos de los cuales un $60 \%$ son menores de 30 años y son ya dos generaciones las que han nacido en el exilio y no conocen el territorio del Sáhara Occidental.

Según datos de ACNUR, en una publicación de 2018, la población saharaui a fecha 31 de diciembre de 2017 es de 173.600 personas que viven en el refugio, de las cuales el 75 $\%$ es población vulnerable, es decir, según la agencia de cooperación española ${ }^{17}$, personas afectadas por problemas relacionados con la desnutrición y la anemia, entre las que se contabilizan:

- Mujeres embarazadas y madres lactantes.

- Menores de edad con anemia crónica.

- Familias monoparentales encabezadas por mujeres (viudas, divorciadas o solteras).

- Otros colectivos con necesidades específicas: personas adultas mayores, personas con diversidad funcional y/o con enfermedades crónicas.

¿Cómo es capaz de sobrevivir esta población donde la mayoría son personas vulnerables? Pues fundamentalmente son dependientes de la ayuda humanitaria de entidades como ACNUR, PNUD, la UE a través de sus programes ECHO, etc. Así como la ayuda humanitaria de diversos países en los que destaca España como primer país donante de ayuda humanitaria al pueblo saharaui en el refugio.

Con todas estas aportaciones y según datos de ACNUR son 125.000 raciones alimentarias diarias las que se proporcionan a los campamentos de refugiados saharauis. Aquí aparece la primera disyuntiva, si ACNUR estima en 173.600 las personas en el refugio, de las cuales el $75 \%$ son vulnerables, es decir 130.200. La ayuda humanitaria no sirve ni para nutrir a la población saharaui vulnerable.

Es cierto que España es el primer país donante al pueblo saharaui con donaciones estimadas entre 5 y 10 millones de euros, dependiendo del año y por lo tanto de la estrategia política desarrollada en cada momento por el gobierno de turno. Pero, también es cierto, que la donación es insuficiente para garantizar unas condiciones de vida mínimamente dignas de esta población.

En este sentido, España obtiene una condición muy ventajosa, por un lado es el primer donante humanitario del pueblo saharaui, pero esta donación es insuficiente lo que logra que, poco a poco, la población en el exilio se debilite y vayan abandonando sus requerimientos políticos para la celebración de un referéndum de autodeterminación con garantías, transparente y justo, bajo el amparo de las Naciones Unidas a través de su Misión de las Naciones Unidas para el Referéndum del Sáhara Occidental (MINURSO).

¿Cuál es la posición oficial del gobierno de España respecto a la causa Saharaui?

Según la web de Ministerio de Asuntos Exteriores del Gobierno de España ${ }^{18}$ :

16 Datos obtenidos de la web de ACNUR: https://eacnur.org/blog/refugiados-saharauis-40-anos-devida-en-los-campos/

17 http://www.aecid.es

18 Datos obtenidos de la web del Ministerio de Asuntos Exteriores: http://www.exteriores.gob.es 
«En lo relativo al Sáhara Occidental, España apoya una solución política, justa, duradera y mutuamente aceptable que prevea la libre determinación del pueblo saharaui en el marco de los principios y propósitos de la Carta de las Naciones Unidas. España apoya el papel central de las Naciones Unidas en la búsqueda de una solución y mantiene su compromiso humanitario con el pueblo del Sáhara Occidental, siendo el primer donante bilateral de ayuda a los campamentos de refugiados».

A priori es una declaración justa y a favor de la causa saharaui, en el que además se muestra el lado humanitario del gobierno como principal país donante de ayuda humanitaria. Pero si analizamos en profundidad esta declaración, lo que está apoyando el gobierno español es la propuesta marroquí de convertir el Sáhara Occidental en una autonomía del Reino de Marruecos ya que esta es la única solución ofrecida y la única que será admitida por Marruecos, país invasor del territorio del Sáhara Occidental y por tanto la única «...mutuamente aceptable...»

Si continuamos leyendo en esta misma web, donde se recoge la estrategia política en materia de asuntos exteriores con el Magreb encontramos, dos párrafos más allá, las siguientes afirmaciones:

«Desde una perspectiva económica, España mantiene intensos vínculos con el Magreb. Las relaciones comerciales e inversiones tienen una importancia particular tanto en Marruecos (España se convirtió en 2012 en el primer socio comercial de Marruecos, siendo además el primer destino africano y árabe de las exportaciones españolas, con 20.000 empresas españolas operando), como en Argelia (España ha sido el primer socio comercial de Argelia en 2013 y 2014 con un volumen de intercambios superior a $15.000 \mathrm{M} \$$, particularmente en el sector energético).»

Es difícil de creer, a tenor de lo que afirma la web de exteriores, que España esté a favor de la celebración de un referéndum justo en el Sáhara Occidental cuando sus mayores socios comerciales del norte de África nos son otros que el país invasor, Marruecos y el país de acogida, Argelia. Parece claro que la política exterior española prioriza los acuerdos comerciales y los interese empresariales sobre la justicia y la resolución de un conflicto que mantiene en el olvido a 173.600 saharauis.

Qué gobierno, por fin, tomará las riendas para la solución de este conflicto, pudiendo incomodar a sus socios comerciales, cuando, citando la misma web:

«El Magreb es uno de nuestros principales suministradores energéticos. Importamos de esta región aproximadamente el $45 \%$ del gas, lo que tradicionalmente ha desequilibrado nuestra balanza comercial.»

Lo cierto es que parece que a nivel gubernamental estamos vendidos a los intereses económicos y energéticos. Parece claro que un intento de solución del conflicto podría llevar a la desestabilización de los acuerdos económicos con Marruecos y también con Argelia.

Eso sin entrar a valorar otras cuestiones como la externalización de las fronteras de la UE donde Marruecos en un socio fiel a las políticas migratorias ${ }^{19}$ :

19 Continuación de los datos obtenidos de la web del ministerio de Asuntos exteriores español. 
«La seguridad en la región constituye una preocupación compartida por España y los países del Magreb. La criminalidad organizada, los tráficos ilegales y el terrorismo internacional activo en el Sahel y Libia representan una amenaza directa para todo el Mediterráneo. Por este motivo, las autoridades españolas trabajan con sus homólogas magrebíes para identificar y prevenir riesgos y cooperar en el ámbito policial y judicial con el fin de evitar la impunidad. Por otro lado, la necesidad de gestionar los flujos migratorios ha impulsado la firma de acuerdos con los países del Magreb, zona de destino y tránsito de muchos inmigrantes que anhelan llegar a Europa. España apoya en este sentido las nuevas políticas migratorias de los países de la zona, como Marruecos. También destaca en esta materia la colaboración con Mauritania.»

Si además a todo esto añadimos que España es también el primer donante de ayuda humanitaria a Marruecos ${ }^{20}$ : «...Marruecos es además el principal receptor de asistencia en materia de vecindad y pionero en negociar nuevos acuerdos en materia migratoria, de pesca o comercial.»

Y que parte de esta ayuda se destina a afianzar la cultura y empresas marroquíes en territorio ocupado como el caso de los 13.385.389 de dólares, equivalentes a 11.916.744,12 de euros, de un proyecto bilateral bajo el amparo de los Objetivos de Desarrollo del Milenio (ODM) desarrollado entre los años 2008 y $2012^{21}$.

La conclusión al respecto es que España se mantiene en una posición muy cómoda con respecto a todos los organismos, socios y países implicados. Con el pueblo saharaui abandera su condición de ser el país que más ayuda destina a la cooperación en los campamentos. Con Argelia muestra el rostro de país colaborador con el pueblo saharaui y realiza acuerdos comerciales muy potentes sobre todo en materia de energía (fundamentalmente importando gas). Con Marruecos se muestra como un país donante de ayuda humanitaria al pueblo saharaui, pero con una donación insuficiente que desalienta la causa y la resistencia saharaui, por otro lado, es también el primer país donante de ayuda humanitaria a Marruecos, colaborando en proyectos de aculturación de la zona ocupada y de mantenimiento de la situación actual. Además tienen grandes intereses económicos comunes, entre los que se encuentran la explotación de los fosfatos del Sáhara ocupado y de la explotación de sus recursos pesqueros y petrolíferos, entre otros.

Con la UE España se muestra como un país que vela por los acuerdos de la Unión, siendo clave en la creación y mantenimiento de los mismos, como por ejemplo, con las acuerdos pesqueros con Marruecos donde muchas capturas se realizan en los caladeros del Sáhara Occidental, hecho completamente ilegal como dicta la ONU. También se muestra firme en las políticas migratorias donde junto a Marruecos crean una política de retención y devolución de inmigrantes externalizando de esta manera las fronteras de la UE.

Con respecto a los Estados Unidos, Marruecos es un enclave estratégico fundamental para el control del Magreb, del estrecho de Gibraltar y del mundo islámico, España colabora en estas cuestiones estratégicas vendiendo armas al reino de Marruecos, a pesar de las prohibiciones de los organismos internacionales de venta de armas a países en conflicto, como en este caso.

En conclusión parece que el gobierno español es uno de los países más beneficiados del mantenimiento del status quo, para no desequilibrar sus estrategias políticas y económicas. Manteniendo en el refugio y en condiciones miserables a ciudadanos españoles

20 Continuación de los datos obtenidos de la web del Ministerio de Asuntos exteriores Español.

21 Según datos de la agencia española de cooperación y desarrollo (AECID) 
y ofreciendo poca colaboración para reconocer sus derechos históricos como ciudadanos españoles.

Nada que ver con la población civil que sigue volcada en el apoyo de la causa y colaborando con el pueblo saharaui. Muchas de estas pequeñas aportaciones de entidades y asociaciones hicieron posible la creación y actualmente el mantenimiento de, entre otras cosas, un sistema educativo en el refugio y en el desierto.

\section{Conclusiones}

El pueblo saharaui desde los primeros tiempos en el refugio, sobre el año 1975, hizo un esfuerzo enorme apostando por la educación con el fin de alfabetizar a una población mayoritariamente analfabeta. A día de hoy, ese esfuerzo ha tenido sus resultados y han sido capaces de articular un sistema educativo en el desierto principalmente en las etapas de infantil y primaria escolarizando a prácticamente el $100 \%$ de la población infantil.. Actualmente el gobierno saharaui está intentando crear escuelas de secundaria suficientes en los campamentos, evitando que la población tenga que continuar sus estudios en el exterior. También están intentando mejorar la formación profesional y están intentando crear una universidad que pueda formar en estudios superiores a parte de la población saharaui.

El pueblo saharaui depende exclusivamente de la ayuda humanitaria. Esta ayuda es insuficiente para alimentar al total de la población saharaui. A pesar de los grandes inconvenientes su apuesta por la educación es constante y siguen mejorando un sistema educativo gracias a la cooperación, fundamentalmente, de entidades españolas y de algunas comunidades autónomas.

El gobierno español es el principal donante de ayuda humanitaria al pueblo saharaui. También es el primer responsable de la situación y no parece tener interés de resolver un conflicto que perdura desde el año 1975 ya que sus intereses comerciales con países como Marruecos podrían verse perjudicados.

El sistema educativo saharaui ha sido capaz de dar respuesta al alumnado con discapacidad creando escuelas de educación especial en cada uno de los campamentos.

La educación en los campamentos contribuye a una mejora del bienestar de la población saharaui y da la posibilidad de formar a las personas para el desarrollo de las tareas necesarias para la organización de los campamentos así como formar a los dirigentes políticos de la RASD. 


\section{Bibliografía}

Aranda, R. R., Arias, S. C. y González, L. (2012) La formación del profesorado saharaui en los campamentos de refugiados de Tindouf. Revista Tendencias pedagógicas, 20.

Bárbulo, T. (2002). La historia prohibida del Sáhara Español. Madrid: Destino.

Barrañeda, I. y Ojeda, R. (coords.). (2016). Sáhara Occidental, 40 años después. Madrid: Los libros de la Catarata.

Diego Aguirre, J.R. (1991). Guerra en el Sáhara. Madrid: Istmo. -(1998). Historia del Sáhara español. Madrid: Kaydeda.

Fiddian-Qasmiyeh, E. (2015). South-South Educational Migration, Humanitarianism and Development. Londres. Ed. Routledge.

Lehbib, B. (2017). El Sistema Educativo Saharaui. Vivencias Diarias. (Recuperado de https://1saharaui.wordpress.com)

Mahmud Awah, B. y Moya, C. (2009). El porvenir del español en el Sáhara Occidental. Madrid.

Ponte, C. (2003) «Escuelas en el Sáhara. El único fruto que crece en el desierto», en Cuadernos de Pedagogía, 328, (pp.14-19). Barcelona: Fontalba.

Soroeta, J. (2009). La posición de la Unión Europea en el conflicto del Sáhara Occidental, una muestra palpable (más) de la primacía de sus intereses económicos y políticos sobre la promoción de la democracia y de los derechos humanos. Revista de derecho comunitario europeo, 34.

Velloso, A. (1993). La educación en el Sáhara Occidental. Madrid. UNED.

- (1998). El desorden mundial y los refugiados. Madrid. UNED.

Velloso, A. y Vinagrero, J. A. (2011). Educación, guerra, dictadura y refugio. Madrid: Sanz y Torres .

- (2016). Educación en Palestina, Sáhara Occidental, Iraq, Guinea Ecuatorial y para refugiados. Madrid: UNED.

\section{Fuentes consultadas en la red}

Web oficial de la RASD:

https://www.nodo50.org/aapscyl/historia/organizacion_rasd.htm

Web de ACNUR:

https://www.acnur.org/es-es/ 
Web del Ministerio de Asuntos Exteriores:

http://www.exteriores.gob.es

Web de CEAS-Sáhara:

http://ceas-sahara.es

Web de la Agencia Española de Cooperación Internacional:

http://www.aecid.es 